\title{
Meiotic Studies in Two Species of Cicer and Their Hybrids
}

\author{
G. Kabir ${ }^{1}$ and R. M. Singh \\ Department of Genetics and Plant Breeding, Institute of Agricultural Sciences \\ Banaras Hindu University, Varanasi-221 005, India
}

Accepted June 19, 1991

Information on the genus Cicer provided by Maesen (1972) clearly indicates that very little cytogenetic work was undertaken in the genus. Due to small size of chromsomes throughout the genus, most of the reports (Ahmed et al. 1952, Meenakshi and Subramanium 1960, 1962, 1963a, 1963b, 1966, 1967, Cobley 1965, Phadnis et al . 1968) were mainly confined to chromosome counts. Some cytological works have been done on some species of Cicer (Mercy et al. 1974, Selim and Yousuf 1975, Ahmed and Godward 1980, Sharma and Gupts 1982, 1983, Lavania and Lavania 1983). Chromosome numbers alone are not adequate for the purpose of a study of interspecific relationship with in the genus and presence of small somatic chromosomes may not reveal minor structural differences (Sharma and Gupta 1983). However, Ladizinsky and Adler (1976) reported the cytogenetic relationship between three species of Cicer and brought new information regarding the origin of cultivated chickpea, C. arietinum. The discovery of $C$. reticulatum (Ladizinsky 1975) from Turkey has aroused a great interest as progenitor of the cultivated chickpea. Morphologically and by their seed protein profile (Ladizinsky and Adler 1975, Kabir and Singh 1988), C. reticulatum is very close to the cultivated species and could be suspected as its wild progenitor. Thus the present study in these two species and their hybrids were undertaken on chromosome association and chiasma frequency using meiosis to draw a valid conclusion on their relationship.

Table 1. Parental lines, hybrids, number of crosses made and hybrid seeds obtained

\begin{tabular}{|c|c|c|c|c|}
\hline Species/Hybrids & $\begin{array}{l}\text { Varieties/ } \\
\text { Strains }\end{array}$ & Source & $\begin{array}{l}\text { Number of } \\
\text { crosses } \\
\text { made }\end{array}$ & $\begin{array}{l}\text { Number of } \\
\text { hybrid seeds } \\
\text { obtained }\end{array}$ \\
\hline C. arietnum & $\begin{array}{l}\mathrm{H}-208 \\
\text { ICC-8923 }\end{array}$ & $\begin{array}{l}\text { AICPIP } \\
\text { BHU, India }\end{array}$ & - & - \\
\hline \multirow[t]{2}{*}{ C. reticulatum } & NEWC-21 & $\begin{array}{l}\text { ICARDA } \\
\text { Aleppo, Syria }\end{array}$ & & \\
\hline & $\mathrm{Jm}-2106$ & $\begin{array}{l}\text { ICRISAT } \\
\text { HYDERABAD, } \\
\text { India }\end{array}$ & - & - \\
\hline $\begin{array}{l}\text { C. arietnum }(\mathrm{H}-208) \times \\
\text { C. reticulatum }(\mathrm{NEWC}-21)\end{array}$ & - & - & 373 & 27 \\
\hline $\begin{array}{l}\text { C. arietnum }(\mathrm{ICC}-8923) \times \\
\text { C. reticulatum }(\mathrm{Jm}-2106)\end{array}$ & - & - & 345 & 30 \\
\hline
\end{tabular}

\section{Material and methods}

Information about the plant materials in this study is summarized in Table 1. Interspecific crosses were acomplished in the experimental field. Buds were pollinated a day after emusculation and, the hybrids and parental lines were grown in the field under uniform nutritional and environmental conditions.

For the study of meiotic behaviour alongwith chromosome assocciation and chiasma frequency young flower buds of suitable sizes were collected between 9 and $10.30 \mathrm{a} . \mathrm{m}$. from

\footnotetext{
1 Present address: Deparment of Botany, Rajshahi University, Rajshahi-6205, Bangladesh.
} 
ten plants of each parents and hybrids. The flower buds were fixed in 1:3 aceto-alcohol to which a small amount of ferric chloride ( $1 \mathrm{~g}$ in $500 \mathrm{ml}$ of aceto-alcohol) was added imparting straw colour. After $48 \mathrm{hr}$ of fixation they were transferred to $70 \%$ ethanol and kept in a refrigerator untill used. Temporary slides were prepared from suitable anthers by acetocarmine smear technique. Data on chromosome association and chiasma frequency was recorded from diakinesis/prometaphase from the same preparations. Photomicrographs were taken from the desired preparations.

\section{Results}

Cytological screening was done from diakinesis to second telophase in ten plants from each parents and two hybrids of Cicer species. Some chromosomal irregularities were observed at different stages which are shown in Figs. 1-12. Two to four plants in all the parents were found with meiotic abnormalities. Rest of the plants were with normal and regular meiosis. Percentage of some common irregularities such as fragments, laggards and bridges in pollen mother cells of the parents and $F_{1} s$ are given in Table 2. Most of the abnormalities were found at first meiotic division. Cytokinesis occured at the end of telophase II and microspores were found to arrange themselves tetrahedrally. On the other hand all the ten plants of both the hybrids were found with meiotic irregularities at all stages of meiosis and their frequency were high than their respective parents. Micronuclei were observed only in the cross of $C$. arietinum (H-208) and C. reticulatum (NEWC-21). Cytokinesis was found to occur at the end of telophase II and microspore arrangement was tetrahedral.

Chromosome association and chiasma frequency of four parents and two $F_{1}$ s were studied from the same preparations of pollen mother cells (PMCs) made for meiotic study. The pollen mother cells containing univalents, bivalents and quadrivalents were observed at diakinesis/ prometaphase I. A total 500 PMCs were studied from ten plants of each parent and hybrid. The data on chromosome association and chiasma frequency were tabulated which are given in Tables 3 and 4.

\section{Discussion}

Cytological screening from the pollen mother cells of ten plant from each parent showed regular and normal meiotic division. However, some irregularities such as lagging chromosomes, chromosome fragments, chromosome or chromatid bridge etc. were observed in some plants with low frequency. The percentages of these irregularities ranged from 1.29 ( $C$. reticulatum, NEWC-21) to 2.67 (C. arietinum, ICC-8923). Among the different type of abnormalities, frequency of lagging chromosome was maximum followed by chromosome fragment and then by bridges. Bridges were recorded only at second anaphase stage in C. arietinum (ICC-8923) and the frequency of it was only $0.38 \%$. It was perhaps due to stickiness of chromosomes. However, Ahmed and Godward (1980) observed bridges at second anaphase in one plant out of ten of $C$. arietinum and they explained its occurance on the basis of crossing over with a ring chromsome. Chromosome fragments were found in all the parents except C. arietinum (NEWC-21). This type of abnormality may be considered as disintegrative which has been reported at first meiotic division in some plant species (e.g., Kinugasa japonica by Haga 1937). Occassional fragments of different sizes and irregularly distributed in $C$. arietinum was reported by Iyengar (1939). Lagging chromosome was observed in all the parents, however, not in all ten plant and it was mostly found at first metaphase. At other stages it was observed but occassionally. This type of abnormality was reported in $C$. arietinum by Iyengar (1939) and Ahmed and Godward (1980). It might be due to the persistence 

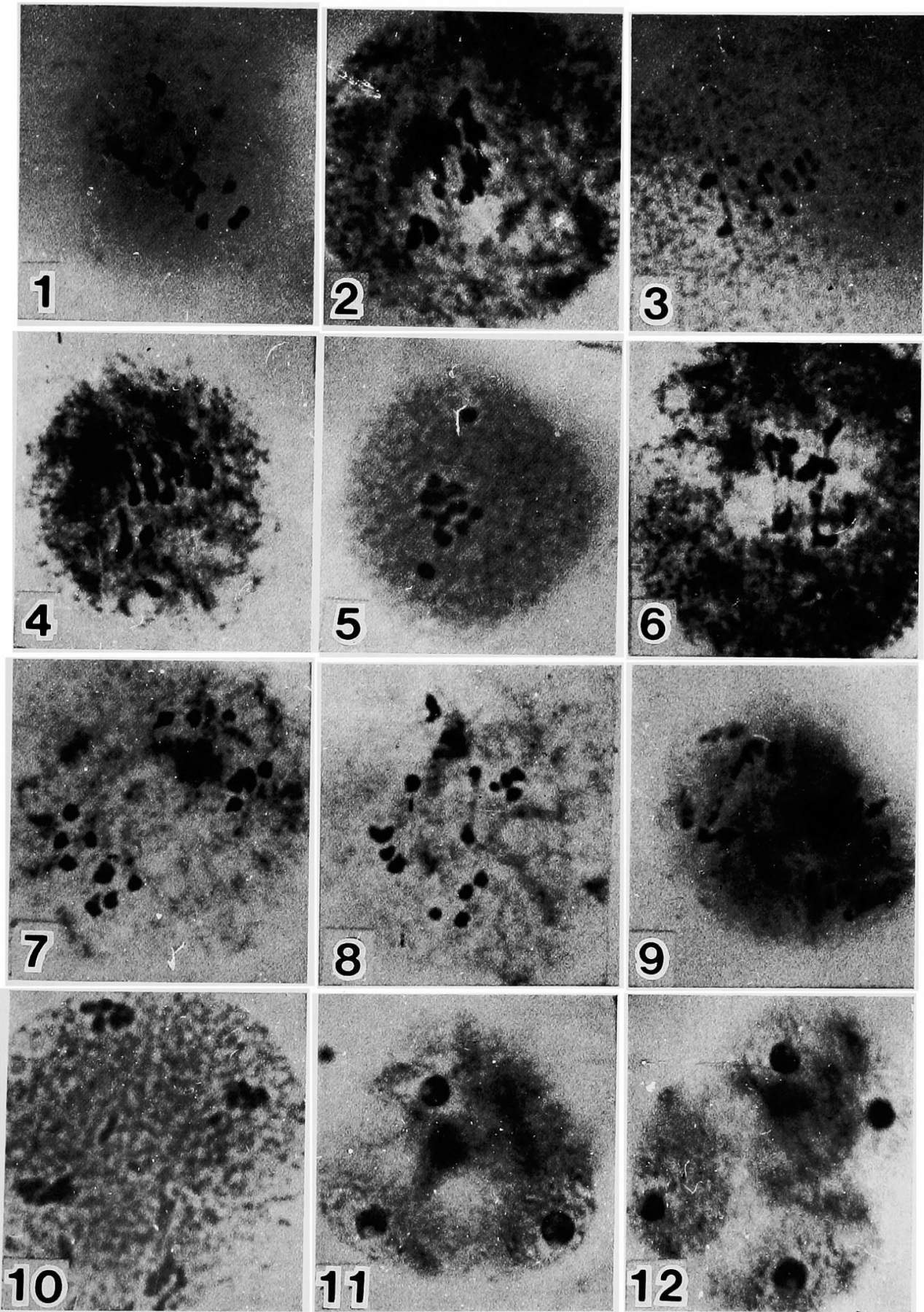

Figs. 1-12. Photomicrographs showing different meiotic stages of parents and hybrids of Cicer species. 1, Metaphase I with eight bivalent chromosomes. 2, Metaphase I with lagging chromosome. 3, Metaphase I with chromosome fragment. 4, Metaphase I with two univalents and seven bivalents. 5, Metaphase I with two univalents and seven contracted bivalents. 6, Metaphase I with one quadrivalent and six bivalents. 7, Anaphase I with equal distribution of chromosomes. 8, Irregular distribution of Anaphase I chromosomes. 9, Anaphase II with chromosome bridge. 10, Telophase II with lagging chromosome and chromosome fragment. 11, Tetrahedral arrangement of microspores. 12, Isobilateral arrangement of microspores. 


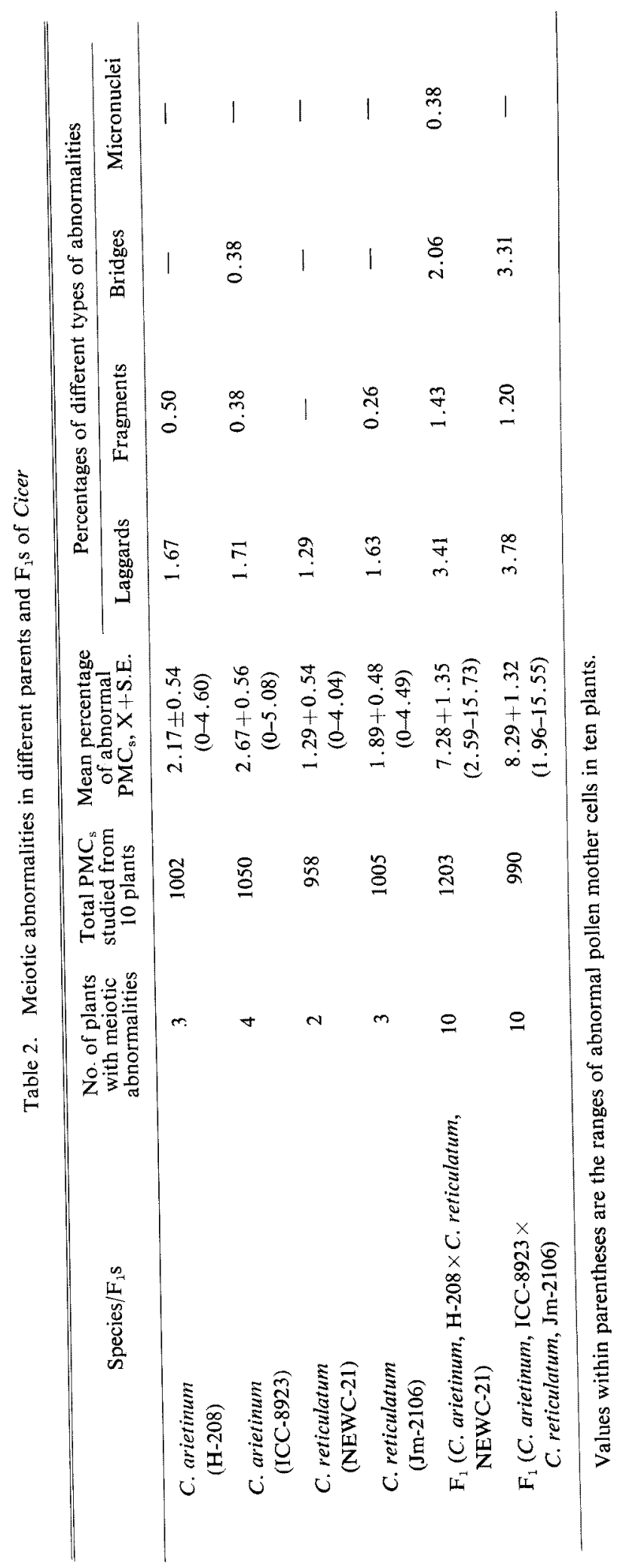



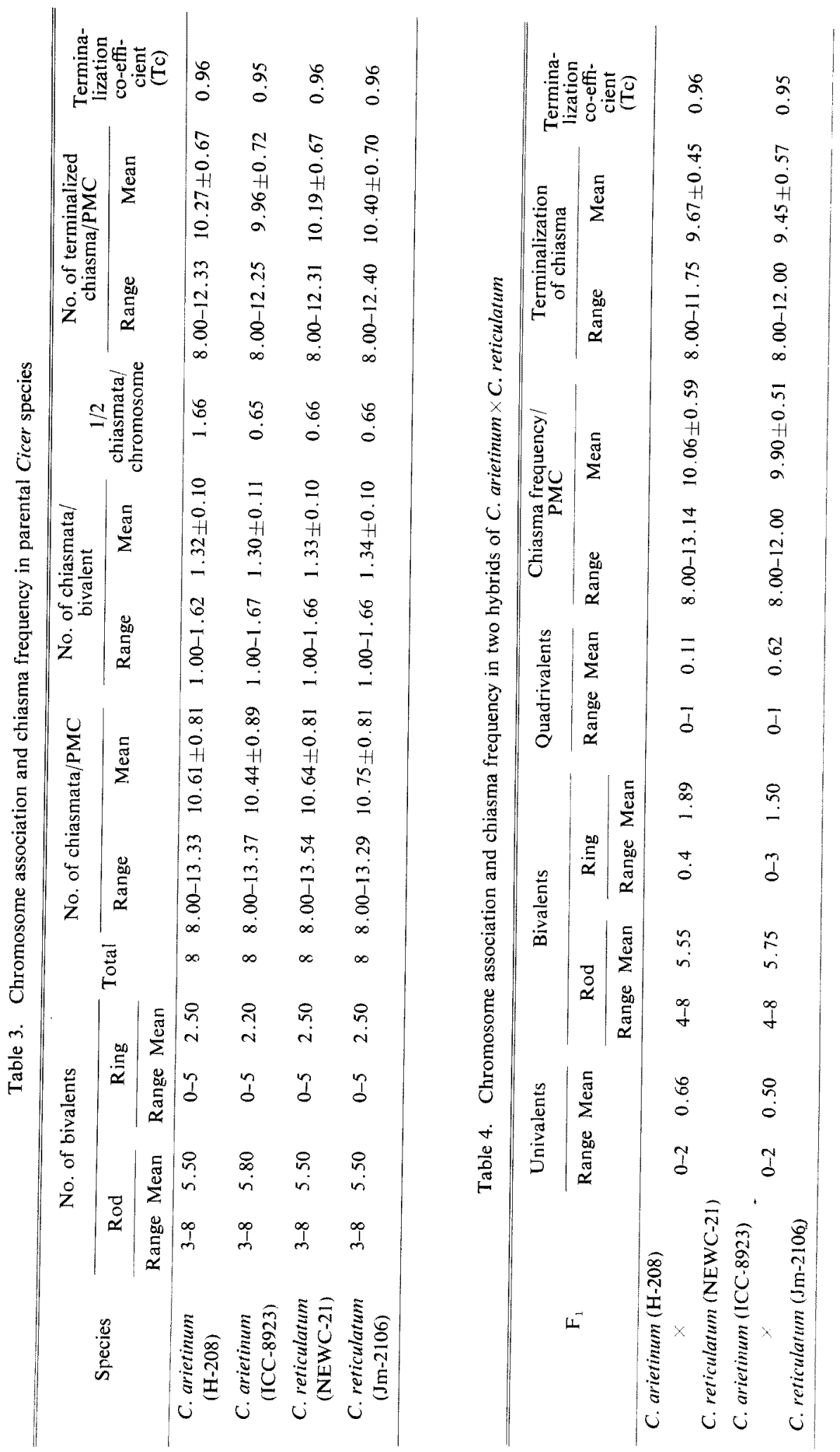
of interstitial chiasma particularly at the first meiotic division. However, congression may be hindered by the repulsion of the other chromosomes on a crowded plate, and in this case one bivalent may form an accessory plate half way between a primary plate and pole (Darlington 1937). Bivalents that do not congress also do not orientate. Non-orientation may also be caused by interlocking and multiple association (Iyengar 1939). Berthelmess (1957) attributed lagging chromsomes accompanied by adhesion of centromeres to the adjacent inner surface of plasma. Adhesion of centromeres of one or more chromosomes of the outer layer of plasma and movement of the other towards the equatorial plate lead to the appeareance of lagging chromosomes.

The $\mathrm{F}_{1}$ of $C$. arietinum $(\mathrm{H}-208) \times C$. reticulatum $(\mathrm{NEWC}-21)$ and $\mathrm{F}_{1}$ of $C$. arietinum (ICC$8923) \times C$. reticulatum $(\mathrm{Jm}-2106)$ were found with higher percentages of meiotic abnormalities $(7.28 \%$ in the former and $8.29 \%$ in the later) than that of their respective parents. However, the differences were statistically insignificant. Despite the irregularities, more than $90 \%$ cells were found with normal and regular meiotic division. Irregularities were mainly lagging chromosomes, chromsome fragments, chromsome or chromatid bridges and micronuclei. In both the hybrids, bivalent was found to lying outside the croweded metaphase plate and occasionally two univalents were seen side by side as well as near the respective poles. Chromatid bridge at anaphase of the first meiotic division was observed only in the $F_{1}$ of $C$. arietinum $(\mathrm{H}-208) \times$ C. reticulatum $(\mathrm{NEWC}-21)$ but no chromosome fragment was found along with the bridge in the same cell by which it may be attributed to the persistence of the interstitial chiasma and not due to paracentric inversion. However, Ladizinsky and Adler (1976a) observed bridges in the hybrid of $C$. arietinum and $C$. reticulatum due to paracentric inversion. Bridges at second anaphase were found in both the hybrids in the present study. Micronuclei were observed only in the hybrid of $C$. arietinum $(\mathrm{H}-208) \times C$. reticulatum $(\mathrm{NEWC}-21)$ which might be due to bivalent lagging chromosomes. The lagging univalents do not give rise to micronuclei but one lost in the cytoplasm (Iyengar 1939). Quadrivalents were observed in both the hybrids. Irregular distribution of chromosome was observed at anaphase of second meiotic division in the $F_{1}$ of $C$. arietinum (ICC-8923) $\times C$. reticulatum $(\mathrm{Jm}-2106)$. Cytokinesis occured at the second meiotic division and microspore arrangement was tetrahedral in both the hybrids and their respective parents.

As a rule, diakinesis is the best stage for studying chromsome association. Contraction is near a maximum and the chromsome pairs are well spread throughout the cell as though by mutual repulsion pairs of homologous chromsomes are still held together at chiasmata but are elsewhere separated (Wilson and Morrison 1973). In the present investigation paired chromosomes at diakinesis in all the parents and $F_{1} s$ of Cicer were found to held together finely at chiasmata. In so many cells prometaphase chromosomes were found to show the maximum contraction and well spread in the cell. Thus the data on chromosome association and chiasma frequency were recorded from diakinesis as well as from prometaphase. All the parents indicated a preponderence of rod bivalents. Mean rod and ring bivalents in $C$. arietinum $(\mathrm{H}-208)$ and both the strains of $C$. reticulatum were same (5.50 and 2.50, respectively). Iyengar (1939) observed the association of rod and ring bivalents in $C$. arietinum found the longest as well as shortest chromosomes to form invariably the rod bivalents. However, the longest chromosomes in all the parents in present study were found to from invariably rod bivalents. No univalent or multivalent was found in any of the species. Ladizinsky and Adler (1976a) observed only bivalents in $C$. arietinum, $C$. ehinospermum and $C$. reticulatum. Similarly Sharma and Gupta (1983) found only bivalents in C. arietnum, C. bijugum, C. cuneatum, $C$. judaicum, $C$. pinnatifidum and $C$. reticulatum. Though regular bivalent formation is the rule, lagging chromosomes in all the species of the present study indicated the presence of structurally altered chromosomes in the complement and accoding to Iyengar (1939) the persistence of 
chiasma results in the lagging of bivalents. Univalents and quadrivalents were observed only in the hybrids of $C$. arietinum $\times C$. reticulatum, although their percentages were very low. The percentages of univalents and quadrivalents were 2.40 and 0.60 in $\mathrm{F}_{1}$ of C. arietinum $(\mathrm{H}$ 208) $\times$ C. reticulatum (HEWC-21), and 3.80 and 1.00 in the $F_{1}$ of $C$. arietinum (ICC-8923) $\times$ C. reticultum (Jm-2106), successively. In these two hybrids, however, the quadrivalent and univalent obtained occasionally indicated that the parental lines differed by a recipıocal translocation and failure of pairing of two chromsomes in some cells. Ladizinsky and Adler (1976a) found univalents, trivalents and quadrivalents in the hybrid of C. reticulatum $\times$ C. arietinum, and only quadrivalents in the hybrid of $C$. arietinum $\times C$. reticulatum. However, the formation of bivalents indicated that different sets of chromosomes were involved in their origin.

Chiasma frequency can be very useful in comparing species and in some cases it may be a more precise parameter than the karyotype itself, since the chiasma formation reflect similarities both in genetic content and in the arrangement of genes (Roy and Singh 1968). Chiasma frequency per cell in C. arietnum (H-208), C. arietinum (ICC-8923), C. reticulatum (NEWC-21) and $C$. reticulatum $(\mathrm{Jm}-2106)$ were $10.61,10.44,10.64$ and 10.75 , respectively. Ladizinsky and Adle1 (1976a) found chiasmata per cell in different varieties of $C$. arietinum, which ranged 10.06 to 14.06 and in C. reticulatum it was 14.23. Sharma and Gupta (1983) studied seven species of Cicer and observed mean chiasma frequency varied from 14.36 ( $C$. reticulatum) to 15.36 (C. bijugum) and found the chiasma frequecies to be independent of chromosome length. The differences of the chiasma frequencies in different parents of Cicer in the present study were statistically significant. However, the highest chiasma frequency was indicative of the fact that recombination index was high in the species involved and it was comparatively low where chiasma frequency decreased. Half chiasmata was 0.66 in C. arietinum $(\mathrm{H}-208)$ and in both the strains of $C$. reticulatum, however, $C$. arietinum (ICC-8923) was found with 0.65 for half chiasmata per chromosome. Terminalized chiasma per cell was highest in Jm-2106 of $C$. reticulatum (10.40) and lowest in ICC-8923 of C. arietinum (9.96). Terminalized chiasma per bivalent was not calculated. However, Iyengar (1939) found terminalized chiasma per bivalent 1.17 in $C$. arietinum. In the present study terminalized chiasma per cell were 10.27 and 9.96 (which stands 1.28 and 1.24 per bivalent) in $\mathrm{H}-208$ and ICC-8923 of $C$. arietinum, respectively. Iyengar (1939) also found terminalized co-efficient (TC) 0.89 in C. arietinum. However, the cultivars H-208 and ICC-8923 of $C$. arietinum were found with 0.96 and 0.95 terminalized coefficient. It was 0.96 in both the strains of $C$. reticulatum.

Chiasma frequency per cell in the $\mathrm{F}_{1}$ of $C$. arietinum $(\mathrm{H}-208) \times C$. reticulatum $(\mathrm{NEWC}-21)$ was 10.06 , while in the $\mathrm{F}_{1}$ of $C$. arietinum (ICC-8923) $\times$ C. reticulatum $(\mathrm{Jm}-2106)$ it was 9.90 . Terminalized chiasma per cell and its co-efficient were 9.67 and 0.96 in the former, and 9.45 and 0.95 in the later, respectively. However, Ladizinsky and Adler (1976a) observed chiasmata per cell in four hybrids of $C$. arietinum $\times C$. reticulatum which ranged from 10.76 to 13.28 . Thus it appear that both the hybrids have close resemblance with their respective parents. The occasional occurance of quadrivalents in both the hybrids were indicative of the fact that the parental lines differed by a reciprocal translocation. The quadrivalent indicated a chromosomal rearrangement between the two species. Thus, by itself, however, can not inhibit the complete fertility of the hybrids. However, a low frequency of univalents were observed side by side outside the plate, and also nearest to the respective poles which might be the pairing without chiasma formation also due to the fact that the univalents were very near to the plate and arranged themselves on it, then splited and the two halves passed to the poles consequently. Univalents may arise due to (i) failure of pairing of short chromosomes (or mentioned above) and (ii) occasionally formation of a trivalent (Iyengar 1939). But no trivalent was observed in both the hybrids, however, the univalents were of short chromosomes. In certain cases univalents occur due to distinct nature of the genomes of the parental speices but in the present 
study regular formation of bivalents in both the hybrids indicated a remarkable similarity between the genomes of two species. It is thus clear that $C$. reticulatum is rather in the range of C. arietinum primary gene pool (Harlan and De Wet 1971) and gene exchange between them is free. Along with this interpretation $C$. reticulatum may be considered also as the wild progenitor of $C$. arietinum.

\section{Summary}

Two species of Cicer and their hybrids were studied meiotically to draw a valid conclusion on their relationship. Meiosis was found to be normal except some irregularities such as lagging chromosomes, fragments, bridges etc. with a low frequency. However, the frequency of irregularities in the hybrids were somewhat high than that of their respective parents. Cytokinesis was found to take place at the end of second telophase and the arrangements of microspores were tetrahaedral. Data on chromosome association and chiasma frequency were recorded from diakinesis as well as from prometaphase. Both the parents and hybrids indicated a preponderence of rod bivalents. Univalents and quadrivalents were observed only in the hybrids. A remarkable similarity was observed between the genomes of the hybrids and their respective parents, and it indicated $C$. reticulatum rather in the range of $C$. arietinum primary gene pool and free gene exchange between them. This study also reflected $C$. arietinum as wild progenitor of cultivated $C$. arietinum.

\section{References}

Ahmed, G. D., Hafiz, A. and Ashraf, M. 1952. Cytological studies of indigenous and exotic gram types. Proc. Pak. Sci. Conf. 4: 16-17.

Ahmed, S. and Godward, M. B. E. 1980. Cytological studies on the cultivars of Cicer arietinum L. from pakistan. Caryologia 33: 55-68.

Berthelmess, A. 1957. Chemica induzierte multiploare mitosen. Protoplasma 48: 546-561.

Cobley, L. S. 1965. An Introduction to the Botany of Tropical Crops. Longmans Green and Co. London. New york. Toronto. 5th imp. 150-151.

Darlington, C. D. 1937. Recent Advances in Cytology. 2nd ed. Blakisten, Phila. pp. 671.

Haga, T. 1937. Chromosome complement of Kinugasa japonica with special reference to its origin and behaviour. Cytologia 8: 137-141.

Harlan, J. R. and DeWet, J. M. J. 1971. Toward a rational classification of cultivated plants. Taxon20: 509-517.

Iyengar, N. K. 1939. Cytological investigations on genus Cicer. Ann. Bot. 3: 271-305.

Kabir, G. and Singh, R. M. 1988. Seed protein electrophoresis in six species and two $F_{1} s$ of Cicer. Proc. Indian Acad. Sci. 98(3): 183-189.

Ladizinsky, G. 1975. A new Cicer from Turkey. Notes from the Royal Botanic Graden, Edinburgh. 34: 201-202.

— and Adler, A. 1976a. The origin of chickpea (Cicer arietinum L.). Euphytica 25: 211-217.

- and $-1976 \mathrm{~b}$. The origin of chickpea as indicated by seed protein electrophoresis. Israel J. Bot. 24: 183-189.

Lavania, U. C. and Lavania, S. 1983. Karyotype studies in Indian pulses. Genetic Agraria 37: 299-307.

Maesen, L. J. G. V. 1972. Cicer L., A Monograph of the Genus with Special Reference to the Chickpea (Cicer arietinum L.), its Ecology and Cultivation. H. Venman and Zonen N. V.-Wageningen, Netherland. p. 342.

Meekashi, G. and Subramanium, M. K. 1960. Tandem satellites in Cicer arietinum L. Curr. Sci. 29: 438439.

- and -. 1962. Variations in the satellited chromosomes of Cicer arietinum L. Proc. Indian Acad. Sci. 55: $15-23$.

- and - 1963a. Nucleolus-satellite relationship at prophase and polysomaty in Cicer arietinum L. Curn. Sci. 32 : $465-467$.

- and - . 1963b. Studies on the Nucleolus. 11. The persisting nucleoli of Cicer arietimum L. Proc. Indian 
Acad. Sci. 57: 73-82.

- and -. 1966. Triploidy in Cicer arietinum L. Caryologia 19: 163-166.

- and -. 1967. Tetrasomaty in the roots of Cicer arietinum L. Proc. Indian Acad. Sci. 66: 192-199.

Mercy, S. T., Kakar, S. N. and Chowdhury, J. B. 1974. Cytological studies in three species of genus Cicer.

Cytologia 39: 383-390.

Phadnis, B. A., Nerkhede, M. N. and Tombre, M. B. 1968. Further studies in polysomaty in root tips of Cicer arietinum L. Proce. Indian Acad. Sci. Sci., 68: 279-283.

Roy, R. P. and Singh, M. K. 1968 . Meiotic studies in the genus Lathyrus. Nucleus 11: 7-12.

Selim, A. R. and Yousuf, S. S. 1975. Meiotic studies in Cicer. Egyptian J. Genet. Cytol. $4: 476$.

Sharma, P. C. and Gupta, P. K. 1982. Karyotype in some pulse crops. Nucleus 25: 181-185.

- and - 1983. Cytological studies in the genus Cicer L. Proc. XV Int. Cong. Genet. New Delhi, 12-21 Dec.

Abst. No. 1257. Oxford and IBH Publishing Company, New Delhi, India.

- and - 1983. Cytogenetics and Origin of Some Pulse Crops. (Ed. Swaminathan, M. S., Gupta, P. K. and

Sinha, U.). Cytogenetics of Crop Plants. Macmillan India Ltd. 405-440.

Wilson, G. B. and Morrison, J. H. 1973. Cytology. Affiliated East-West Press Pvt. Ltd. New Delhi. p. 319. 